\title{
La movilización etnopolítica afromexicana de la Costa Chica de Guerrero y Oaxaca: logros, limitaciones y desafíos
}

\author{
América Nicte-Ha López Chávez*
}

Perfiles Latinoamericanos, 26(52) | 2018

DOI: $10.18504 / \mathrm{pl} 2652-010-2018$

Recibido: 10 de mayo de 2016

Aceptado: 10 de julio de 2017

\begin{abstract}
Resumen
Este artículo señala las características de la movilización etnopolítica afromexicana de la Costa Chica de Guerrero y Oaxaca, sus demandas, las respuestas del Estado por medio de políticas multiculturales, así como las tensiones existentes, con el objetivo de identificar los logros, limitaciones y desafíos de la movilización. Primero se describe el contexto sociopolítico del México multicultural, después se formula un perfil sociodemográfico, para posteriormente analizar la trayectoria de lucha, conflictividad y contradicciones de la organización colectiva. Para cumplir su propósito, el artículo se auxilia de conceptos teóricos del marco del neoliberalismo multicultural y desarrolla un estudio de caso de la Costa Chica de Guerrero y Oaxaca de 1997 a 2016, con base en la revisión de minutas y relatorías de reuniones hito, y en las interacciones entre los principales actores.
\end{abstract}

\begin{abstract}
This article indicates the characteristics of the Afro-Mexican ethnopolitical mobilization of the Costa Chica of Guerrero and Oaxaca, their demands, the responses of the State, as well as the existing tensions, with the general objective of identifying the achievements, limitations and challenges of the mobilization. It begins establishing the sociopolitical context of the multicultural Mexico, then formulates a sociodemographic profile, and analyzes the trajectory of struggle, conflict and contradictions of collective organization of the Afro-Mexicans. In order to achieve the general objective, the article applies theoretical concepts of the neoliberal multicultural framework and develops a case study of the Costa Chica of Guerrero and Oaxaca from 1997 to 2016, based on the revision of minutes, rapporteurships of milestone meetings and interactions between the main actors of the mobilization.
\end{abstract}

Palabras clave: afromexicanos, multiculturalismo neoliberal, México, Costa Chica de Guerrero y Oaxaca, afrodescendientes en América Latina, políticas del reconocimiento, identidad.

Keywords: Afro-Mexicans, neoliberal multiculturalism, Mexico, Costa Chica of Guerrero and Oaxaca, Afrodescendants in Latin America, politics of recognition, identity.

* Doctora en Derecho y Ciencia Política por la Universidad Autónoma de Madrid | ame.lopez24@gmail. com 


\section{Introducción ${ }^{1}$}

E

América Latina y México, la concepción de la alteridad cultural está representada por los pueblos indígenas (Wade, 2000). En contraste, las poblaciones afrodescendientes apenas están logrando visibilizarse como un grupo culturalmente diferente que también compone la diversidad y pluralidad de este último país. Por medio de un estudio de caso, el presente artículo aborda las características de la movilización etnopolítica afromexicana y sus demandas, además de las respuestas del Estado por medio de políticas multiculturales y las tensiones existentes. El objetivo es resaltar los logros, límites y desafíos de dicha movilización para conseguir el reconocimiento constitucional y poder participar en la construcción de la agenda pública. Con ello se pretende aportar nuevo conocimiento que abone al campo de los estudios afromexicanos que han trabajado en la realidad social del proceso organizativo de la movilización etnopolítica afromexicana de la Costa Chica de Guerrero y Oaxaca (Hoffmann \& Lara, 2012; Lara, 2010, 2014; Lewis, 2012; Quecha, 2016).

La identidad es un tema complejo que aparecerá constantemente a lo largo del texto. Y por principio debe acotarse que en México y en la Costa Chica de Guerrero y Oaxaca existen múltiples categorías que se refieren a un mismo sujeto con ascendencia africana. ${ }^{2}$ Por eso y aunque académicamente son categorías con significados diferentes, utilizaré afrodescendiente, afromexicano, negro o moreno de forma indistinta. ${ }^{3}$ Wade (2008) señala que para referirse al sujeto de estudio lo ideal es usar el término con el que se autoidentifica. En consecuencia, en este documento se tomará en cuenta que las comunidades de la Costa Chica se autoidentifican sobre todo con la categoría de moreno o negro (Hoffmann, 2006; Lewis, 2012). Asimismo, se utilizarán como sinónimos las palabras pueblos, poblaciones o comunidades para referirse a las poblaciones con ascendencia africana que habitan en la Costa Chica de Guerrero y Oaxaca. Estos términos son aceptados por las organizaciones afromexicanas y aparecen en las constituciones locales de Guerrero y Oaxaca (Lara, 2014). Cuando me refiera a la Costa Chica, estaré englobando a los estados mexicanos de Guerrero y Oaxaca.

1 Este artículo forma parte de la investigación para mi tesis doctoral Afrodescendientes en América Latina. Estudio de caso de la movilización etnopolítica afromexicana de la Costa Chica de Guerrero y Oaxaca, México (1997-2016).

2 Afrodescendiente, afromexicano, afrocosteño, afromestizo, afromepha, afroindígena, negro, negro de la costa, negro afromexicano, costeńo, moreno, etcétera.

3 Decidí utilizar la categoría de afromexicano debido a que existe cierto consenso entre instituciones y organizaciones. Sin embargo, estoy a favor de la autoidentificación y/o el autorreconocimiento. 
De acuerdo a Melucci (1999), un movimiento social es una forma de acción colectiva que se basa en un sentido de solidaridad, el cual en algún punto desarrolla ciertos conflictos que desembocan en rupturas. En las interacciones entre las organizaciones afromexicanas se encuentran la solidaridad, el conflicto y la ruptura. No obstante, ante esta última se presenta también un patrón de reconciliación y renegociación. Otros académicos, como Hoffmann (2006), concuerdan en que no es posible llamar movimiento social a esta forma de acción colectiva.

Mientras que la clave para referirse correctamente a una acción colectiva es identificar el proceso en el que un grupo de individuos establecen sus similitudes y deciden actuar en conjunto, cabe puntualizar que el potencial de movilización es una herramienta útil para conocer dicho proceso (Melucci, 1999). Sin embargo y aunque las definiciones teóricas son clasificaciones en las que no caben todos los casos, pues las circunstancias históricas y sus particularidades espaciales y culturales cambian las formas en las que se expresan y actúan en colectivos, utilizaré el término de movilización.

Para entender la problemática social analizada, el artículo retoma el marco teórico multicultural. No obstante, se debe aclarar que no existe una definición aceptada de multiculturalismo y cualquier intento por llegar a ella puede dejar algún elemento fuera (Kymlicka, 2007; Wieviorka, 2014). No obstante, en este documento multiculturalismo y políticas multiculturales tendrán el mismo significado, pues ambos conceptos se refieren a políticas aplicadas por el Estado en respuesta a las demandas de grupos de población específicos, en este caso, de las organizaciones afromexicanas. Tomo, para este contexto, el término de multiculturalismo neoliberal de Hale (2002, 2005, 2006), el cual se refiere a la interacción del multiculturalismo y el neoliberalismo, que resulta en políticas multiculturales que aparentemente contribuyen a la inclusión de un grupo, pero que a la vez lo limitan. Las principales políticas multiculturales aplicadas en América Latina son el reconocimiento constitucional, el otorgamiento de títulos de la propiedad colectiva de la tierra, legislación, herramientas para luchar contra el racismo y la discriminación, y políticas de acción afirmativa (Agudelo, 2015; Hooker, 2010, 2011; Van Cott, 2000a, 2000b, 2001).

Para cumplir con el propósito del artículo, se inicia reconstruyendo el contexto sociopolítico del México multicultural, para luego elaborar un perfil sociodemográfico cuyo fin es conocer el volumen, localización geográfica y características socioeconómicas del afromexicano de la Costa Chica; para esto se han usado datos del Consejo Nacional de Población (Conapo), del Consejo Nacional de Evaluación de la Política de Desarrollo Social (Coneval) y del Instituto Nacional de Estadística y Geografía (INEGI). 
Para desarrollar el estudio de caso se han organizado y sistematizado en orden cronológico algunas ${ }^{4}$ de las actividades, intervenciones de instituciones gubernamentales en procesos de la movilización afromexicana como campañas de sensibilización, e interacciones entre organizaciones afromexicanas con instituciones gubernamentales que se dieron entre 1997 y 2016, por medio del análisis de declaratorias, minutas, pronunciamientos y relatorías emanados de reuniones significativas de organizaciones afromexicanas como México Negro, África, ECOSTA y ÉPOCA, por mencionar algunas de las más activas en ese periodo. ${ }^{5}$ Ello se complementa con entrevistas abiertas y semiestructuradas que realicé a líderes de organizaciones afromexicanas, estudiantes de la Universidad de los Pueblos del Sur (UnISUR), afromexicanos de la sociedad civil, y representantes de instituciones gubernamentales y académicas; añado una revisión bibliográfica y aplico algunos conceptos del marco teórico del neoliberalismo multicultural. Debido a que las demandas y las respuestas van apareciendo en el análisis, las consigno en la última sección.

\section{Contexto y dinámicas del México pluricultural y multicultural}

México se construyó como un Estado nación homogéneo bajo la identidad mestiza (López, 2014). Sin embargo, en México cohabitan mestizos, pueblos indígenas y poblaciones afrodescendientes. El tránsito hacia un Estado nación heterogéneo que reconoce la pluralidad viene de finales de los sesenta y se prolongó en toda la década de 1970 (Baltazar, Luna \& Olvera, 2008), justo cuando el país atravesaba una crisis política y económica que resultó en el surgimiento de protestas sociales como el movimiento estudiantil de 1968 (Castellanos, 2011) o las movilizaciones de comunidades indígenas que protestaban en contra de la castellanización y homogeneización cultural operadas por el indigenismo integracionista, que ulteriormente se tradujeron en la implementación de los modelos de educación bilingüe e intercultural bilingüe.

La caída en los precios del petróleo y la reducción del gasto público intensificaron la crisis económica en la década de 1980, mientras que la ruptura del control del Partido Revolucionario Institucional (PRI) desatada por los nuevos actores transnacionales y la implementación de las reformas neoliberales, propició una crisis política. La crisis económica se reflejó en la masiva expulsión de campesinos a la ciudad y en el incremento de las desigualdades sociales

4 Por cuestiones de espacio omití intervenciones, acciones e interacciones de organizaciones de apoyo, universidades y el papel que han jugado los organismos internacionales en estos procesos.

5 Son significativas porque han establecido consensos o herramientas de organización y movilización. 
(Castellanos, 2011; Lewis, 2012), en tanto que la política llevó a la pérdida de control y hegemonía del PRI y supuso el arribo de actores como el Partido de la Revolución Democrática (PRD). Así, "en la década de 1990 se observaron importantes transformaciones sociopolíticas que fueron un referente para las luchas por el reconocimiento de derechos ciudadanos y culturales en México" (Lara, 2010: p. 312).

En 1994 se atestiguó la emergencia de un sujeto indígena políticamente organizado con el Ejército Zapatista de Liberación Nacional (EZLN) (Castellanos, 2011). Los zapatistas exigían acabar con la corrupción, dar fin a la opresión por parte del Estado, resolver la falta de servicios básicos como agua y electricidad y terminar con el abuso del poder. Pero su principal exigencia era la autonomía, pero sin que esta se basara en el reconocimiento de la diferencia cultural. La demanda de tierra no era tan fuerte porque la reforma agraria de 1917 ya estipulaba su repartición (Gobierno Federal y EZLN, 1996; Burguete, 2003: pp. 197, 204). Este recuento muestra las diferencias entre los reclamos del movimiento zapatista y los de la movilización afromexicana.

México se comprometió entonces a garantizar la libre determinación de los pueblos indígenas. Sin embargo, las contradicciones y limitaciones del multiculturalismo neoliberal que Hale $(2002,2005,2006)$ ha denunciado, se manifiestan cuando la garantía de la libre determinación y autonomía fueron concedidas de tal manera que no rebasaran los límites del marco jurídico para asegurar la unidad nacional y la hegemonía del Estado. El movimiento indígena fue referente para los afrodescendientes en América Latina (Agudelo, 2010a: p. 3, 2015: p. 5), y para Guerrero y Oaxaca, un ejemplo de la lucha por los derechos, territorio, autodeterminación y la construcción de herramientas jurídicas que después facilitaron la movilización y organización afromexicanas en estas entidades (Lara, 2014).

La interacción del multiculturalismo con el neoliberalismo queda expresada en el marco de la aplicación de las reformas neoliberales y del proceso de descentralización. México abrazó las políticas de agencias internacionales financieras y de desarrollo - el Banco Mundial, el Banco Interamericano de Desarrollo- para combatir la pobreza, esto es, las de organismos "que condicionaban sus financiamientos a la incorporación de la variable étnico-racial en los proyectos de desarrollo" (Lara, 2010: p. 313). Estas agencias tenían incorporado en sus agendas el discurso multicultural al poner en marcha proyectos que contenían la política del reconocimiento. Por su parte, el Estado mexicano había implementado mecanismos de contención social basados en preceptos racistas como el positivismo o las teorías científicas de la evolución -especialmente desde la segunda mitad del siglo XIX — que se tradujeron en políticas de control, asimilación y contención social como el mestizaje y el indigenismo 
del siglo xx; esta última se puso en marcha bajo el régimen del PRI (Hoffmann \& Lara, 2012; Saldívar, 2014). Fue en el contexto de la irrupción en el escenario político de otros actores, entre ellos el partido de izquierda PRD, y de las políticas del reconocimiento, que diversos grupos de la Costa Chica, bajo la identificación afromexicana, se organizaron y emergieron buscando tener una voz a nivel internacional, nacional y local (Lara, 2010).

\section{Perfil sociodemográfico del afromexicano de la Costa Chica en 2015}

\section{Datos demográficos con base en la Encuesta Intercensal de 2015}

Los resultados de la Encuesta Intercensal de 2015 (EIC, 2015) del INEGI, indican que de los 119530753 de mexicanos (en viviendas particulares habitadas), 1381853 (1.2\% de la población total) se reconocen como afromexicanos, es decir, 12 de cada 1000 personas. Guerrero (7.61\%), Oaxaca (5.89\%) y Veracruz $(4.07 \%)$ son los estados con mayor porcentaje de este tipo de identificación. La población de Guerrero sumaba entonces 353321 personas, es decir, 3\% de la población nacional, de las cuales, el $33.92 \%$ se consideraba indígena y el 7.61\% afromexicano. La población de Oaxaca era el 3.3\% del total nacional con 3967889 individuos, de los cuales, el $65.73 \%$ se autoidentificaba como indígena y el 5.89\% como afromexicano (INEGI, 2015a).

Los porcentajes de autorreconocimiento que se han utilizado para generar el perfil suman las variables se considera y se considera en parte, ya que si se descartan se contribuye a la esencialización de la cultura y de la identidad (Appiah, 1994, 2005; Benhabib, 2002), lo mismo que a repetir la invisibilización y exclusión. El 1.2\% que se reconoce como afromexicano es un porcentaje significativo que organizado podría lograr avances.

\section{Ubicación geográfica}

De acuerdo a la EIC 2015, la presencia afromexicana predomina en Guerrero, Oaxaca y Veracruz (INEgi, 2015a). Este artículo se enfoca en las dos primeras entidades, las cuales comparten la Costa Chica, la región con más presencia afromexicana (INEGI, 2015c, 2015d). Ziga (2015) afirma que no se puede entender la emergencia del afromexicano si no se entiende la Costa Chica. Se trata de un espacio territorial, cultural, económico y político en el que el afromexicano se ha insertado, apropiado y relacionado con los demás grupos que lo habitan. Es también la región en donde surgieron las organizaciones 
pioneras para el rescate de la herencia cultural africana y para demandar el reconocimiento constitucional (Hoffmann, 2006; Ziga, 2015). A decir de Gloria Lara, es un espacio territorial en el que,

la movilización humana y el intercambio comercial implicaron la circulación de productos culturales (comida, vestimenta, conocimientos e ideas). Las prácticas culturales específicas se alimentaron de las diferencias de los grupos sociales asentados en la región (en este caso afrodescendientes, indígenas mixtecos, chatitos, amuzgos y mestizos), sin que esto se tradujera en espacios de asentamiento fijo (Lara, 2008: p. 42).

La Costa Chica es rica en recursos naturales donde sobresalen actividades económicas como la ganadería, la agricultura, la pesca y el comercio (CDI, 2012; CNDH, 2016; Lara, 2008; Lewis, 2012). También se caracteriza por la dependencia económica (créditos, seguros, fertilizantes), los intereses de los partidos políticos, la violencia en la vida social y la nula aplicación de la justicia en comunidades pequeñas (CNDH, 2016; Lewis, 2012). Además del histórico acaparamiento de tierras por parte de las estructuras económicas de poder desde la etapa colonial (Lara, 2008; Lewis, 2012), son notables la concentración del ejercicio de la actividad ganadera en una minoría, el escaso apoyo crediticio a los campesinos — principalmente después de que entró en vigor el Tratado de Libre Comercio de América del Norte (TLCAN) — (Lewis, 2012; OvermyerVelázquez, 2010) y el abuso en el comercio de la pesca por parte de una cooperativa (CNDH, 2016). Todo ello ha mermado el desarrollo de la región y la distribución equitativa de los bienes y recursos. Efectivamente, la Costa Chica es rica en recursos naturales, pero esta riqueza la acaparan los grupos dominantes.

\section{Indicadores de pobreza, rezago social y marginación ${ }^{6}$}

\section{Índices de pobreza en 2010 y de rezago social en 2015}

El porcentaje de pobreza en Guerrero es de $86.71 \%$ y el de Oaxaca de $81.73 \%$ : altos grados de pobreza que también se encuentran en los municipios de la Costa Chica. Sin embargo, hay otros, de población predominantemente indígena,

6 Para Guerrero seleccioné los quince municipios de la Costa Chica más nueve que registran autoidentificación de hasta el 6.80\%. Para Oaxaca tomé como punto de partida Santiago Tapextla (85.91\%) y delimité en Valerio Trujano (30.34\%). Cuando me refiera a los municipios oaxaqueńos y guerrerenses, se trata en específico de los mencionados. 
que los superan (CONEVAL, 2010; INEGI, 2015b, 2015c, 2015d, 2015e). De acuerdo al Coneval, "el índice de rezago social es una medida ponderada que resume cuatro indicadores de carencias sociales (educación, salud, servicios básicos y espacios en la vivienda" (2017, párrafo 2), un rubro en el que Guerrero y Oaxaca ocuparon en 2015 el primer y segundo lugar, con una tendencia que oscila entre un grado de rezago medio y alto (CONEVAL, 2015).

\section{Índice absoluto de marginación}

La marginación es un proceso estructural producto del patrón histórico de desarrollo socioeconómico de un país que repercute en la estructura productiva y que, por lo tanto, es excluyente de ciertos grupos sociales (Conapo, 2015; De la Serna, 2010). En este aspecto, Guerrero, Chiapas, Oaxaca y Veracruz son los de mayor marginación en México. Los municipios guerrerenses varían sus grados de marginación entre alto y muy alto, y los oaxaqueños van de medio a muy alto (Conapo, 2010a: p.25, 2010b: pp. 121-124, 2010c: pp. 195, 198-199, 2015). De hecho, los municipios de La Montańa, en Guerrero, de población indígena son los más marginados del país. Y la costa oaxaqueña, a su vez, presenta grados de marginación muy alto, alto y medio. Hay municipios en la Sierra Sur, Mixteca y Valles Centrales de Oaxaca con presencia afromexicana y grados de rezago muy altos.

Los resultados de este perfil sociodemográfico invitan a reflexionar sobre si el reconocimiento constitucional como un grupo culturalmente diferente y la aplicación de políticas públicas específicas podrían devenir en una mejora en la calidad de vida y en una verdadera inclusión al desarrollo nacional. Barry (2001) argumenta que, si un grupo sufre exclusión, no es por ser culturalmente diferente, sino porque su inclusión en las dinámicas económicas es débil.

\section{Movilización etnopolítica afromexicana de la Costa Chica de Guerrero y Oaxaca, 1997-2016. Un estudio de caso}

\section{Proceso de organización y gesta de la movilización}

El antecedente afromexicano se da entre 1970 y principios de 1990, periodo en el que se desarrollaron movimientos y luchas sociales en la Costa Chica que requirieron la organización social. Entre los acontecimientos más significativos de este tipo se cuentan el movimiento guerrillero de 1970, la lucha agraria que enfrentó a caciques y campesinos por disputas de espacios territoriales, el reclamo 
de cambios políticos a nivel nacional y municipal, la pugna por el poder político cuando se dio el derrumbe del PRI y el auge del PRD entre finales de $1980 \mathrm{y}$ principios de 1990, y la denuncia de abusos de los caciques y autoridades locales en el marco de los derechos humanos (Lara, 2008; Ziga, 1998, 2015).

En ese contexto, los entonces negros o morenos de la Costa Chica de Guerrero se unieron en 1992 al movimiento indígena que fue renombrado como Consejo Guerrerense 500 Años de Resistencia Indígena, Negra y Popular, y que había nacido en 1991 a raíz del quinto centenario de la llegada de los españoles a tierras americanas (Sarmiento, 2004). En Oaxaca, además del antecedente mencionado hubo otros que se dieron al interior de los almacenes rurales y consejos comunitarios de abasto en la década de 1980 (Lara, 2008; Ziga, 1998, 2015). Los primeros tintes de organización de corte cultural, a decir de uno de sus líderes, se dieron en la comunidad de José María Morelos, Huazolotitlán.

Entre 1991 y 1999 la Casa del Pueblo difundió información sobre la herencia cultural africana y se llevó a cabo el Primer Encuentro de Música y Danza Indígena. De acuerdo a Ziga (2008), ese evento supuso la reconfiguración de la danza de la tortuga y el inicio de la promoción de la música y danzas de la región, especificando que contaban con elementos culturales de herencia africana. En 1996, con apoyo del Centro Coordinador para el Desarrollo Indígena de Jamiltepec (CCDI) y la Casa del Pueblo, se creó "El Cimarrón”, primer programa radial transmitido por medios oficiales y dedicado a la cultura negra (Reyes, I., comunicación personal, 24 de febrero, 2017).

Estas actividades fueron financiadas y promovidas por la Casa del Pueblo y el CCDI, lo que confirma que existía intervención gubernamental, probablemente en respuesta al programa "La Tercera Raíz", que puso énfasis en rescatar la herencia cultural africana (Hoffmann, 2006; Lara, 2010; Reynoso, 2005). Lewis (2012: pp. 55-188) relata la manera en que instituciones gubernamentales y académicas fueron creando elementos de origen africano entre la década de 1980 y la de 1990. Entonces, ¿existen realmente elementos culturales de origen africano, o fueron construidos artificialmente?

La organización política de los afrodescendientes comenzó en enero de 1997, cuando el religioso trinitario Glyn Jemmott convocó a una reunión a la que asistieron los que se convertirían en líderes de la movilización. Allí surgió la idea de visibilizar la historia y herencia cultural africana mediante un encuentro cultural al que llamaron Encuentro de Pueblos Negros (Reyes, I., comunicación personal, 24 de febrero, 2017). Lara explica que los actores locales que abrazaron la cuestión afrodescendiente eran mayoritariamente "personas que tenían una profesión o ejercían un cargo de autoridad en su comunidad. Estas condiciones posibilitaban cierta capacidad de movimiento, acceso a recursos de información, de contactos extracomunitarios y de prestigio social [...] podía[n] abrir 
posibilidades de allegarse a recursos públicos en el reclamo de derechos como grupo étnico" (Lara, 2010: pp. 316, 321).

El Primer Encuentro de Pueblos Negros se dio en marzo de 1997 en El Ciruelo, Pinotepa Nacional, Oaxaca, y se enfocó en proporcionar las bases históricas de la llegada de africanos a la Nueva Espańa y sus aportaciones al Estado nación. Según los organizadores, esto permitiría que los asistentes conocieran sus raíces y comprendieran el origen de la actual situación política, económica y social del pueblo negro. Chávez (2010) afirma que el padre Jemmott pensó que quizá los negros emprenderían la acción social si tenían una identidad cultural común. Es decir, la identidad fue la primera herramienta de movilización de la afromexicanidad.

La primera interacción con funcionarios públicos se dio durante el III Encuentro, en Cuajinicuilapa, Guerrero que fue celebrado del 10 al 14 de marzo de 1999. Glyn Jemmott invitó al entonces diputado local Néstor Ruiz a sumarse a la acción colectiva, al mismo tiempo que solicitó su colaboración para posicionar el tema en el Congreso guerrerense. Ruiz confirma que este primer intento de sumar a políticos a la cuestión "negra o afro" no tuvo éxito, pues los debates de las políticas del reconocimiento de la diferencia cultural aún no tenían auge en la región. Y añade que intentó que se discutiera el tema en el Congreso durante su legislatura, entre 1999 y 2001, pero no hubo éxito (Ruiz, N., comunicación personal, 30 de agosto, 2015).

A inicios del siglo XXI se dieron las cumbres de Santiago de Chile en 2000 y de Durban, Sudáfrica, en 2001, consideradas un hito de la movilización afrodescendiente. Aunque en la Costa Chica no tuvieron eco, a nivel federal se tradujeron en una serie de derechos entre los que se insertaron algunos relacionados con los pueblos indígenas, además de que se legisló contra el racismo y la discriminación. La organización cultural y articulación política no brotó del seno de las comunidades. Fue inducida por un actor externo, Jemmott, y la abrazaron líderes y personas que poseían capitales políticos, culturales, sociales y, en algunos casos, condiciones socioeconómicas favorables. Por otro lado, de 1991 a 2008 el movimiento se enfocó en la reconstrucción de los elementos culturales, tuvo sus primeras interacciones de corte político y se desarrollaron procesos que llevaron a la constitución de la mayoría de las organizaciones que actualmente se encuentran activas. México Negro, se constituyó en 1997, ECOSTA YUTI CUII, sumó a sus líneas de trabajo a los afrodescendientes en 2005, ÉPOCA se constituyó en 2005. ÁFrICA, A. C. se constituyó en 2007, odECA y PÚRPURA, en 2008. En la siguiente década apareció Socpinda. Por tanto, siguiendo a Melucci (1999), es en este momento que un grupo de individuos y organizaciones conjuntan sus similitudes y su lucha por el reconocimiento constitucional y deciden actuar unidos por medio de la movilización. 
Para trazar una ruta que permitiera avanzar en el reconocimiento constitucional, el entonces Colectivo ÁfriCA con el apoyo del CCDI convocó en noviembre de 2006 en Santiago Jamiltepec, Oaxaca, al taller "Construcción de una Iniciativa de Ley de Derechos y Cultura de los Pueblos Negros". 7 Dicho taller publicó un pronunciamiento en el que destacaba el reclamo del reconocimiento constitucional como eje político de la movilización. Pero las características territoriales y geográficas de la región también quedaron plasmadas en ese documento pues la ganadería, agricultura y pesca son la base de la reproducción material y espiritual del afromexicano (Pronunciamiento, 2006). Si bien la demanda de derechos colectivos de la tierra no tuvo peso pues el ejido y la propiedad comunal de inicios del siglo xx lo habían satisfecho en cierta forma (Burguete, 2003; Lewis, 2012).

Para discutir con más profundidad los temas tratados en el taller de noviembre de 2006 y contar con una mayor participación de las comunidades, en julio de 2007 fue celebrado el Primer Foro Afromexicano en José María Morelos, Huazolotitlán, Oaxaca. Este foro buscaba la convergencia e identificar estructuras organizacionales que abonaran al avance del reconocimiento constitucional (Relatoría de las mesas de trabajo del Primer Foro Afromexicanos, 2007). También reunió a representantes de otros estados como Veracruz y de otros países como el líder afrocolombiano Carlos Rúa, cuya exposición "encauzó los contenidos de la etnicidad en términos políticos y jurídicos y subrayó la lucha contra la discriminación, defensa de la diversidad cultural y defensa de la naturaleza” (Lara, 2010: p. 323). En esta relatoría se plasma por primera vez la petición de implementar instrumentos para luchar contra el racismo y la discriminación. Por tanto, es posible que haya sido en este momento que se adoptaron las dos posiciones que refiere Hooker (2010): autodefinirse como un grupo culturalmente diferente, y como un grupo víctima de discriminación racial.

En mayo de 2009 se constituyó la Red de Organizaciones de Pueblos Negros, una acción que evidencia el primer intento de trabajo en red o en colectivo de las organizaciones. Posteriormente, esta red cambió su nombre a Red por el Reconocimiento Constitucional del Pueblo Negro de México (RCPNM) (Reyes, Rodríguez \& Ziga, 2012).

El XIII Encuentro de Pueblos Negros tuvo lugar en el Pitayo, Cuajinicuilapa, Guerrero, en marzo de 2011, evento en el que se ratificó la declaratoria

7 Francisco Ziga comenta que la decisión de convocar al taller la tomó sin consultar al director del Centro Coordinador. Mucho menos a la Delegación Oaxaca (Ziga, F., comunicación personal, 19 de marzo, 2017). 
del Primer Foro Afromexicano de 2007. Entre las intervenciones de entonces y de interés para este artículo, resalta el rechazo a la Ley de Reconocimiento de Derechos, Cultura y Organización de los Pueblos y Comunidades Indígenas de Guerrero, porque, a decir de un alumno de la UNISUR, "muchos diputados de Guerrero, desconociendo la historia del pueblo afro, entran en la defensa y nos meten en la ley indígena $[\ldots]$ sin conocer nuestra historia se están atreviendo a legislarnos" (México Negro, 2011: párrafo 6).

La intervención del alumno ejemplifica las tensiones y desencuentros entre afrodescendientes y legisladores en cuanto al posible interés en el tema para obtener beneficios políticos. También muestra la influencia del discurso de la diferencia que amplía brechas entre grupos culturalmente diferentes (Appiah, 1994). Sin embargo, como Hooker (2011) y Lewis (2012) señalan, los pueblos indígenas y afrodescendientes están muy lejos de ser distintos y de dejar de interactuar. El entonces representante de la Secretaría de Asuntos Indígenas (SAI), aprovechó para anunciar que esta dependencia había creado el Departamento de Atención al Pueblo Afromexicano. Este fue el primer espacio de representación en una institución gubernamental concedida a los afromexicanos de Oaxaca. Finalmente, en la relatoría se mencionaba por primera vez la falta de organización y unidad en la movilización (México Negro, 2011).

La Red de Organizaciones de los Pueblos Negros organizó en Charco Redondo, Villa de Tututepec, Oaxaca, entre el 21 y el 23 de octubre de 2011, el Encuentro de los Pueblos Negros de la Costa Chica en Movimiento por su Reconocimiento Constitucional. De lo más trascendente fue que se acordó utilizar la categoría afromexicano para efectos jurídicos y políticos de la movilización, ${ }^{8}$ conservando la autodenominación local. Por otro lado, también se lanzó la idea de trasladar la movilización al plano nacional, inició el acompañamiento e intervención de instituciones académicas como la UNAM o la Universidad Michoacana de San Nicolás de Hidalgo y nació la Red Afromexicana (Resolución Primer Foro: Los Pueblos Negros en Movimiento por su Reconocimiento Constitucional, 2011).

El 10 de julio de 2013 se constituyó el Colectivo Nacional Afromexicano (Conafro) integrado, a excepción de académicos y personas independientes, por las mismas organizaciones que forman la RCPNM y la Red Afromexicana (Minuta de la reunión de trabajo de la Comisión de Seguimiento del Encuen-

8 El término afromexicano apareció en la Ley de Pueblos y Comunidades Indígenas de Oaxaca de 1998. Era "necesario dar seguimiento a una categoría que une dos referencias históricas, en cuanto al origen Afro haciendo referencia al pasado de las raíces en África y, Mexicano, en tanto forman parte del conjunto nacional. El segundo argumento se refería a la conflictividad que tiene utilizar el término negro, en tanto que para muchos pobladores en la costa, sigue siendo un término discriminatorio" (Lara, 2014: p. 165). 
tro Afromexicano, 2013). Esta interacción subraya el principal rasgo de esta movilización que consiste en gestar organismos para agilizar la organización, y que ellos se integran mayoritariamente por las mismas personas, aunque muchas veces no llegan a operar.

El 8 de diciembre de 2013 se constituyó en Pinotepa Nacional la Red de Mujeres de la Costa Chica, A. C. (Remco, A. C.). Su constitución expresa el empoderamiento de las mujeres afromexicanas, especialmente de Oaxaca, al configurar una organización propia y unirlas en una red que les permite establecer una agenda común que incide en su desarrollo (Remco, A. C., s/a: párrafo 5). La Red cuenta con una colaboración y financiación significativa del Fondo Semillas, el Instituto de Liderazgo Simone de Beauvoir (ILSB) y el Instituto de la Mujer Oaxaqueña (IMO), factor que posiblemente ha contribuido en su empoderamiento y en que sea uno de los actores más activos de la movilización (Notas de trabajo de campo, agosto y noviembre de 2015).

Socpinda convocó a una reunión el 10 de enero de 2015 para preparar el Evento Piloto del Segundo Coloquio Internacional de Afrodescendientes en Pinotepa Nacional, Oaxaca. La siguiente declaración refleja la falta de unidad y organización;

Históricamente se vislumbraba un movimiento afro unificado, integrado, comprometido con dar una buena imagen a nivel internacional. Incluso creamos un mecanismo para mantenernos unidos. Lo que sucede es que no se sabe trabajar en red ni en colectividad. Este mecanismo duró tres meses por los intereses de cada organización, algunos no toleran ser coordinados por gente nueva. Socpinda proponía una unificación para no quedar mal ante la comunidad internacional que nos visitaba. Hubo compañeras y compañeros que bloquearon la llegada de las personas de las comunidades al coloquio. Al estilo de los viejos políticos (Ramírez, I., comunicación personal, 3 de abril, 2017).

Así pues, en enero de 2015 se llevó a cabo el Evento Piloto rumbo al Segundo Coloquio Internacional de Afrodescendientes. El resultado más interesante fue la formación de una mesa permanente de organizaciones afromexicanas en acuerdos comunes (Relatoría Evento Piloto, 2015). Se trató de un nuevo intento de encontrar un mecanismo de trabajo colectivo, que finalmente cristalizó en la conformación de una Coordinación Nacional de Organizaciones Afromexicanas (CNOA), la cual buscaba construir una agenda unificada de la movilización para intentar trascender al nivel nacional sumando a otros estados a la movilización (Minuta de trabajo, 26 de enero de 2015). Surgió así un órgano integrado por la mismas organizaciones y personas de la Red Afromexicana, la RCPNM y el Conafro. 
La CNOA logró convocar a tres reuniones. La cuarta estaba programada para el 9 de mayo de 2015 en Pinotepa Nacional. Dado que eran tiempos electorales y varias personas estaban involucradas de manera directa en esa actividad, las reuniones se pospusieron sin retomarse después. Se comentó entonces que "de la Coordinación y de Conafro solo queda el chat de Facebook, no se puede con tanto protagonismo. Las mismas personas seguimos movilizándonos y colaborando, desde otros espacios" (Amaro, B., comunicación personal, 5 de marzo, 2017).

El 8 de noviembre de 2015 Socpinda lanzó una convocatoria para realizar una reunión de organizaciones afromexicanas y poder celebrar el Segundo Coloquio Internacional Afrodescendiente y el xvi Encuentro de Pueblos Negros. México Negro, a su vez, propuso fusionar el Segundo Coloquio con el xvi Encuentro. La propuesta fue rechazada y los eventos se desarrollaron por separado en un contexto de hostilidad (Nota personal tomada durante el Segundo Coloquio). Ramírez comentó que "el Encuentro de Pueblos Negros estaba para realizarse en octubre y lo movieron una semana antes del Coloquio. Esto complicó a actores nacionales e internacionales su participación en ambos eventos (Ramírez, I., comunicación personal, 3 de abril, 2017).

En este escenario de fracturas se concretó el xvi Encuentro de Pueblos Negros en la comunidad del Azufre, Tututepec, Oaxaca, en noviembre de 2015. Los Encuentros se habían financiado con donaciones y apoyo de instituciones gubernamentales locales y estatales, ello estuvo a cargo de la Red Integra. El financiamiento fue significativo porque permitió la asistencia de los mascogos de Coahuila y de Glyn Jemmott. Iturralde \& Más Ferrer (2015) relatan que, de acuerdo a los organizadores, fue uno de los eventos más concurridos por afromexicanos de la sociedad civil, organizaciones afromexicanas, instituciones gubernamentales, nacionales, locales y estatales, académicos, y candidatos de partidos políticos y extranjeros.

En esta interacción hay un par de cuestiones. La primera es la presencia de los mascogos, pues son los que han tenido la menor interacción con la movilización. La segunda es que, a pesar de la ruptura, el ambiente hostil, lucha por el poder y el protagonismo, el Encuentro ha sido el más exitoso en cuanto a asistencia. Por tanto, cabe indagar si el financiamiento de la Red Integra determinó el éxito de asistencia, o si fue por el cambio de fechas a raíz de la ruptura de la dinámica de organización con Socpinda.

En diciembre de 2015 se conformó el Consejo Académico de la Cátedra Itinerante de Mujeres Afromexicanas (CIMA) cuyas reivindicaciones se basan en el empoderamiento integral de la mujer. En los Fundamentos Académicos de este Consejo resalta que han determinado que el fortalecimiento de la identidad de la mujer como negra afromexicana es uno de sus ejes (Cátedra de Mujeres 
Afromexicanas, 2016). En torno a esto y respecto de la identidad, filósofos, políticos y académicos como Appiah (1994, 2005), Barry (2001), Benhabib (2002), Cowan (2001), Hooker (2011), Kymlicka (1995) y Phillips (2007) han mencionado que la cultura y la identidad son temas que van ligados y están en constante cambio y movimiento y que por ello son complejas y a la vez flexibles. Entonces, imponer una categoría construida tiene consecuencias como su esencialización y politización y, sobre todo, en el hecho de que más allá de reparar daños e injusticias, el reconocimiento de la diferencia puede llevar a la profundización de conflictos y divisiones entre grupos culturales.

Appiah (1994) refiere que el reconocimiento cultural puede crear un patrón de comportamiento; de afromexicano, para este caso. Entonces, si ser reconocido como afromexicano significa seguir ciertos lineamientos acordes a su definición, estamos ante una esencialización de la cultura e identidad afromexicana ¿Qué pasa si yo me considero afromexicana, pero no cumplo con los requisitos de la definición oficial? ¿Qué pasa si no me identifico con la categoría afromexicana, pero sí con otra como la de costeña?

Por otro lado, Appiah (1994) y Sansone (2007), afirman que dentro de la misma cultura negra existen subculturas. Esto puede ser aplicado a la Costa Chica, en donde las personas de ascendencia africana, así como los elementos culturales que podrían tener origen africano tienen una raíz diversa. Esto se complementa recordando que la configuración de la Costa Chica ha sido compleja, pluriétnica y de fronteras porosas, lo que ha producido la construcción y multiplicación de diversas identidades que se refieren a un mismo sujeto. Siguiendo a Agudelo (2010b: p.10), estamos ante una "de las identidades negras en plural". Es muy difícil que haya consenso acerca de que sea una sola categoría.

Hoffmann (2006) y Lewis (2012) argumentan que en México y la Costa Chica puede haber elementos de origen africano, pero que no existe una identidad colectiva afromexicana y no está comprobado al cien por ciento que los elementos que se han utilizado para configurar la actual identidad afromexicana sean de origen africano. De hecho, no hay elementos puramente africanos, pues estos se han ido transformando y configurando. Así pues, establecer la categoría de afromexicano como la oficial puede llevar a conflictos. La concepción de la afrodescendencia es distinta en Guerrero y en Oaxaca. En consecuencia, se dan confrontaciones en relación con decidir cómo llamarse para ser reconocidos: "hay que dejar de pelear por cosas secundarias como el nombre. Lo importante es avanzar en cosas productivas" (Mojica, T., comunicación personal, $10 \mathrm{de}$ marzo, 2017).

En noviembre de 2016 se dio el XviI Encuentro de Pueblos Negros en Ometepec, Guerrero cuyo acuerdo más importante fue que el encuentro de 2017 sería en Mata Clara, Veracruz (Quecha, 2016). Es un paso muy significativo, 
pues por primera vez en veinte años, el Encuentro saldrá de la región, lo cual podría ser el hito de dar a la movilización un carácter nacional.

De acuerdo a las acciones, intervenciones e interacciones analizadas, se puede afirmar que las características de la movilización afromexicana son los antagonismos, la lucha por el poder, la dicotomía del multiculturalismo neoliberal entre ser líder de una acción colectiva y ser político o funcionario público, es decir, ser juez y parte (Postero, 2007) — lo cual conduce en general a la politización de la identidad y a la cooptación de la movilización (Albó, 1994; Albó, 2002; Canessa, 2016; Lucero, 2008; Martínez, 2006; Overmyer-Velázquez, 2010)—, la politización del movimiento — dado que algunos de sus líderes pertenecen a partidos políticos y otras personas se reconocen como afromexicanos en tanto signifique recibir algún beneficio (CDI, 2012; Lewis, 2012)—, la configuración de organismos que son dejados de lado, y el empoderamiento de mujeres afromexicanas.

\section{Acciones e intervenciones de instituciones gubernamentales}

La Comisión Nacional para el Desarrollo de los Pueblos Indígenas (CDI) comenzó a interactuar con las comunidades afromexicanas "ante la demanda de asignación de partidas presupuestales de algunos municipios [...] que se declararon 'municipios afromexicanos'" (Lara, 2010: p. 326). En mayo de 2011, el CDI realizó la Consulta para la Identificación de Comunidades Afrodescendientes de México, con el objetivo de identificar las comunidades afrodescendientes. Una observadora de la consulta en Guerrero comentaba que:

La primera pregunta fue que cómo querían ser nombrados y hubo un poco de polémica, porque mucha gente no entendía el término afromexicano. También nosotros teníamos que decirles qué es afromexicano, de dónde venían, cómo llegaron a las costas, porque también se cuentan muchas historias del barco en el que naufragaron. A mí en lo personal no me gustó tanto cómo se llevó a cabo ese trabajo. Yo siento que fue más bien como una simulación de que estaban trabajando, fue una embarradita porque realmente no fue hacia toda la población. La CDi ya llevaba su plan de estudio, eso no era lo que la comunidad quería porque ellos ya tienen su modo de vida (Vargas, E., comunicación personal, noviembre, 2013).

El desarrollo de esta consulta muestra tensiones. Por un lado, parece que la respuesta de la CDI fue más por presión que por decisión y apertura al tema. Por el otro, expresa las dificultades metodológicas de incorporar el tema "afro" 
a su agenda. Probablemente la consulta se dio para abonar en las acciones que el Estado debía realizar de cara a las recomendaciones del Comité para Eliminar la Discriminación Racial (CERD) y para apaciguar la presión de la comunidad internacional y de las organizaciones afromexicanas.

El Conapred y el Movimiento por la Diversidad Cultural elaboraron La guia para la acción pública contra la discriminación y para la promoción de igualdad e inclusión de la población afrodescendiente en México (Conapred, 2011a) y México comenzó a implementar instrumentos jurídicos y herramientas para la lucha contra el racismo y la discriminación desde 2001; ${ }^{9}$ sin embargo, debieron pasar diez ańos para aplicar un instrumento específico para la población afromexicana.

En febrero de 2012, México presentó ante el CERD dos informes sobre sus acciones respecto al reconocimiento e inclusión de la población afromexicana. El CERD respondió con algunas observaciones entre las que destaca el punto 10: "A pesar de reiteradas recomendaciones y solicitudes al respecto, la situación de los afrodescendientes se encuentra invisibilizada. [...] [Por tanto,] el Comité reitera la solicitud hecha al Estado parte que proporcione información sobre los afrodescendientes" (CERD, 2012: p. 2). El INEGI inició entonces un proceso para formular la pregunta que incorporaría la variable afrodescendiente en el Conteo Intercensal de 2015.

El primer paso del INEGi fue lanzar una campaña de sensibilización en Cuajinicuilapa, Guerrero el 28 de junio de 2013. Por su parte, la Secretaría de Asuntos Indígenas y Comunidades Afromexicanas de Guerrero (SAICA), con el apoyo del Conafro, proclamó en San Nicolás, Guerrero, la campaña de sensibilización "Orgullosamente Afromexicano", del 6 al 17 de agosto de 2013 (Minuta de la reunión de trabajo de la comisión de seguimiento del Encuentro Afromexicanos, 2013). Cabe observar que la campaña de sensibilización del INEGI duró un día, cuando para llegar a una verdadera incidencia estos procesos requieren proyectos de largo plazo. Por otra parte, la Conafro implementó una campaña de sensibilización que duró más tiempo y fue apoyada con infraestructura gubernamental gracias a la presencia de García Zavaleta en la SAICA. Esto muestra el desinterés del Estado hacia el tema y la manera en que las organizaciones aprovechan su acceso a las instituciones.

9 En 2001 se reformó el artículo $1^{\circ}$ de la CPEum que prohíbe todo tipo de discriminación (Párrafo reformado en el DOF-04-12-2006 y 10-06,2011, CPEUM, 2016). En 2003 se decretó la Ley Federal para Prevenir y Eliminar la Discriminación, que creó el Conapred (Conapred, 2005) y en mayo de 2005, esta oficina elaboró la Primer Encuesta Nacional de Discriminación (Conapred, 2011b), y lanzó el Primer Programa Nacional para Prevenir y Eliminar la Discriminación. En 2010 llevó a cabo la Segunda Encuesta Nacional Sobre Discriminación (Conapred, 2010), y en abril de 2012 se publicó en el Diario Oficial de la Federación el Programa Nacional para la Igualdad y No Discriminación. 
El primer censo piloto se hizo del 6 al 17 de agosto de 2013 en Guerrero (Cuajinicuilapa), Campeche, Ciudad de México y Sonora. Mireya Quiroz, alumna de la UNIsUR, relata su experiencia de dicho censo en Cuajinicuilapa:

El error estuvo en las personas que fueron a hacer el conteo, pues no llegaron a muchas casas. Yo les pregunté [a las personas encargadas del conteo] ¿quién estuvo a cargo de la colonia Loma del Carmen?, porque a mi casa nunca llegaron. Llegaron hasta donde se cansaron. Nada más. Muchos se saltearon. Contaban una casa y se saltaban dos. Se hizo por barrios y en las comunidades de Cuajinicuilapa, supuestamente fue en donde era más notable la población afro, o sea en Cuaji y sus alrededores, pero pues no llegaban a todas las casas [...] también haz de cuenta que los que fueron a hacer el conteo, como que no estaban en sí, sensibilizados, o sea, lo vieron más bien como un simple trabajo, les iban a pagar y ya. Porque si hubieran ido así sensibilizados, por lo menos hubieran tenido la noción de lo que estaban haciendo (Quiroz, M., comunicación personal, 29 de enero, 2014).

La declaración revela las tensiones existentes - pues se experimentaron, aunque en diferentes contextos-y dinámicas similares a las que sucedieron durante el proceso de consulta de la CDI. Un personal falto de preparación, así como estructuras y herramientas de aplicación inadecuadas. El primer escenario es que el INEGI haya tenido una verdadera disponibilidad, pero la novedad del tema le impidió realizar el censo de manera correcta. El segundo es que no había voluntad política e implementó el censo por compromiso y presión política.

Nuvia Mayorga, entonces directora nacional de la CDI, anunció en agosto de 2013 la inclusión de la población afromexicana en los programas y proyectos de esta instancia, así como la designación de un representante en el Consejo Consultivo de Guerrero (CDI, 2013). Este fue el segundo espacio de representación concedido a un afromexicano. Se percibía con esto un cambio en la actitud de las instituciones, aunque lento e inducido por la presión internacional y local. Si bien queda por ver el margen de acción e incidencia que los afromexicanos tendrán en esos espacios. De acuerdo a Bulmaro García, "la Subsecretaría Afromexicana de Guerrero es más un acto de hecho que de derecho. No hay presupuesto etiquetado para los afromexicanos, no hay poder de toma de decisión" (García, B., comunicación personal, 14 de noviembre, 2013). Estamos ante la política del neoliberalismo multicultural del "sí, pero" (Hale, 2002), también llamada de domesticación (Mitchell, 2004) o de asimilación cívica (Parekh, 2000).

En Oaxaca, por otra parte, se aprobó la iniciativa de reconocimiento constitucional presentada por la exdiputada perredista Leticia Martínez, que entró en vigor en septiembre de 2013. Se reformaron los artículos 1 y 16 del título prime- 
ro de la Constitución del Estado de Oaxaca (CPEo, 2016). Ruiz aclaraba que la iniciativa "se logró por un voto que los diputados pactaron de último momento con un diputado del PRI. A partir de ahí, hubo un desencuentro entre la sAI y las organizaciones" (Ruiz, N., comunicación personal, 30 de agosto, 2015).

Todo esto muestra las divergencias de posiciones, desencuentros y fracturas que suceden entre las organizaciones afromexicanas de Oaxaca, pues mientras ÉPOCA y México Negro apoyaban la iniciativa de Leticia Martínez, ÁfRICA, Socpinda, ECOSTA YUTU CUII, entre otras, estaban a favor de la presentada por la SAI, que pedía la reforma de 42 artículos de la CPEO y la denominación negro afromexicano (Pronunciamiento que hacen las Organizaciones Civiles y Autoridades Municipales del Pueblo Negro Afromexicano, 2013). Aunque la iniciativa la había presentado la diputada Martínez del PRD, fue admitida por el pacto con el diputado del PRI. Esto es una expresión del interés político en la cuestión afromexicana.

La exdiputada federal por el PRD, Teresa Mojica, promovió en octubre de 2013 la iniciativa de ley 1448-1PO2-13 para reformar los artículos 2, 27, 28 y 115 de la Constitución Política de los Estados Unidos Mexicanos (CPEUM) (Mojica, 2013, 18 de octubre). Mojica realmente tenía confianza en que la iniciativa fuera aprobada; sin embargo, se la rechazó. La lucha durante el periodo legislativo para conseguir el reconocimiento constitucional es incuestionable. No obstante, aunque tocó puertas, emprendió cabildeos y campañas de sensibilización para los diputados, no logró que apoyaran su iniciativa. Esto muestra el desconocimiento y desinterés que había del tema de parte de los legisladores $y$ un posible racismo institucional que ella misma denuncia (Mojica, T., comunicación personal, 20 de diciembre, 2013).

Fue en abril de 2014 que en los artículos 8-14 de la Sección II de los Derechos de Pueblos Indígenas y Afromexicanos de la Constitución Política del Estado de Guerrero (CPEG) quedó plasmado el reconocimiento del pueblo afromexicano (CPEG, 2016). Hasta el momento no me ha sido posible identificar quién presentó esa iniciativa de reforma constitucional. Teresa Mojica y Bulmaro García han comentado que fue una cuestión de voluntad e interés político. Pero es indispensable ver qué tanta viabilidad —en cuanto a estructura legal-comporta la demanda de un reconocimiento constitucional equiparando los derechos de los afromexicanos con los conquistados por el pueblo indígena. Conapred (2015) refiere que es necesaria una transformación constitucional, ya que los afromexicanos no tienen cabida en las estructuras legales disponibles a modo de comunidad equiparable con las indígenas, como lo han propuesto Avendaño (2011) y la CDI (2012).

Respecto a la inclusión de la variable afrodescendiente en la eIC 2015, Benigno Gallardo considera que la participación del INEGI ha sido un gran avance, 
pues convirtió a los afromexicanos en "el primer grupo social del país al que le han preguntado: '¿cómo quieren llamarse?”' (Gallardo, B., comunicación personal, 26 de agosto, 2015). Aun así, algunas personas difieren de esta opinión, pues se quejaron en relación con el modo de aplicar la encuesta. Ángel Feria, quien al momento de la aplicación de la encuesta radicaba en Puebla, compartió su experiencia:

Hoy, mi hija, mi esposa y yo contestamos la encuesta de INEGI con orgullo: SÍ SOMOS NEGROS, cabe mencionar que el encuestador no usó el termino NEGRO como marca la pregunta, solo me preguntó ¿SE CONSIDERA AFROMEXICANO? le pedí que leyera la pregunta completa a los encuestados y me respondió que les dijeron que no utilizarán el término NEGRO porque la gente podría ofenderse, y que muchos encuestados no sabían que es afromexicano y que contestaban: NO, YO SOY 100\% MEXICANO. Les daba vergüenza utilizar la palabra negro (Feria, Á., comunicación personal, 17 de marzo, 2017).

Karina López Regalado, del Departamento de Participación y Consulta de la SAI, quien se encontraba en Juchitán, Oaxaca, al momento de la aplicación de la encuesta, también compartió su experiencia: "Ayer me hicieron la encuesta, una chica, muy amable ella, cuando llegó a la pregunta la leyó, me miró y me dijo: es que ha de saber usted que en México hay negritos de esos que vienen de África, pero están no sé dónde por allá, lejos, mejor sigo. Me dio ternura, pero a la vez hace evidente el desconocimiento y la importancia de agregar esta pregunta a la Encuesta. Ni siquiera me dejó contestar si sí o no" (López Regalado, K., comentando su experiencia a Beatriz Amaro, 5 de marzo, 2015).

Las tres experiencias censales (Quiroz, Feria y López) tuvieron lugar en diferentes estados (Guerrero, Puebla y Oaxaca), pero la actitud de los encuestadores fue similar: falta de preparación metodológica, desconocimiento y/o negación del tema. Es probable que estas dinámicas se den no por la inexperiencia de las instituciones en tanto a la novedad del sujeto en sus agendas y estructuras, sino por falta de voluntad política y resistencia hacia el tema, que se podría explicar por un racismo institucional.

Respecto a las demandas de las organizaciones afromexicanas, se puede enumerar las siguientes:

1. Reconocimiento constitucional a nivel federal y estatal, modificación de la legislación secundaria, y armonización de la ley.

2. Inclusión de la variable afromexicana en el ejercicio censal de 2020.

3. Campañas de sensibilización, información y visibilización. 
4. Políticas de acción afirmativa en áreas de:

- Educación: inclusión en los libros de texto, planes y programas de la historia y aportes de los africanos y sus descendientes al país, concesión de becas y de matrículas del 5\% en bachillerato y educación superior, formación y capacitación del personal docente, creación de la universidad afromexicana y/o de la escuela campesina afromexicana, programas de educación intercultural y formación de nuevos liderazgos.

- Cultura y acción simbólico-cultural: difundir la cultura afromexicana material e inmaterial, recuperación de la memoria histórica, establecer el día afromexicano y el mes de la herencia negra.

- Espacios de representación en instituciones políticas y culturales.

- Creación de instituciones afromexicanas.

- Salud: acceso a servicios básicos, reactivar y promover la medicina tradicional, poner atención a epidemias, atender las problemáticas específicas de la mujer, implementar programas de educación sexual para jóvenes, contar con médicos preparados, y que haya disponibilidad de medicamentos.

- Economía: implementar proyectos productivos de desarrollo en actividades como la agricultura, ganadería, pesca, forestales y de turismo.

- Visibilización mediática y demandar el contenido discriminatorio de los medios.

5. Territorio: ser consultados en el marco de la Convención 169 de la oit; implementación de instrumentos para la defensa de los recursos naturales, del territorio y conservación del medio ambiente; programas de protección de zonas contra megaproyectos. ${ }^{10}$

6. Mecanismos para luchar contra el racismo y la discriminación racial.

7. Inclusión en el Plan Nacional de Desarrollo.

8. Formulación y aplicación de política públicas.

\section{Políticas de acción afirmativa para afromexicanos}

La acción afirmativa proporciona un trato preferencial en el acceso o distribución de ciertos recursos y servicios, así como a determinados bienes, y a un determinado grupo que haya sufrido discriminación, todo con el objetivo de mejorar la calidad de vida y compensar por las injusticias del pasado

10 Néstor Ruiz relata que las tierras de Santo Domingo están siendo explotadas por una compañía extranjera que produce sandías (Minuta de Encuentro, 2013). No se han experimentado escenarios, como en el caso de Colombia u Honduras, de desplazamientos forzados o intervenciones violentas. 
(PNUD/SEGIB, 2010). Sin embargo, esto mismo conlleva el riesgo de que haya una esencialización de la cultura y que aumenten las prácticas racistas y xenófobas debido al trato preferencial (Dietz, 2017). Para alcanzar grados de justicia se puede utilizar el enfoque transformativo o afirmativo. Los cuadros 1, 2 y 3 muestran las políticas de acción afirmativa implementadas en la Costa Chica.

\begin{tabular}{|c|c|c|c|}
\hline Variable & Año & Política & Descripción \\
\hline Simbólica-cultural. & 1998 & $\begin{array}{l}\text { Museo de las culturas afromestizas en } \\
\text { Cuajinicuilapa }\end{array}$ & $\begin{array}{l}\text { Derivado del programa "Nuestra Tercera } \\
\text { Raíz", del Conaculta }\end{array}$ \\
\hline Simbólica-cultural. & 2012 & $\begin{array}{l}\text { Programa para el fortalecimiento de la } \\
\text { cultura indígena y afromexicana }\end{array}$ & $\begin{array}{l}\text { En el marco del programa Estrategias } \\
\text { para Abatir la Pobreza Indígena en Gue- } \\
\text { rrero de la SAICA }\end{array}$ \\
\hline $\begin{array}{l}\text { Representación en } \\
\text { instituciones cultu- } \\
\text { rales y políticas. }\end{array}$ & 2012 & $\begin{array}{l}\text { Subsecretaría para Asuntos Afromexica- } \\
\text { nos de la SAICA. } \\
\text { Enlace afromexicano en Acapulco y de } \\
\text { una coordinadora operativa para acciones } \\
\text { de visibilidad e interacción. } \\
\text { Delegado afromexicano en el Consejo } \\
\text { Consultivo de la CDI. }\end{array}$ & $\begin{array}{l}\text { El primer representante afromexicano fue } \\
\text { Bulmaro García Zavaleta. } \\
\text { El segundo representante es Benigno } \\
\text { Gallardo de la Rosa, quien a la vez fue el } \\
\text { primer representante afromexicano en la } \\
\text { CDI-Guerrero. }\end{array}$ \\
\hline $\begin{array}{l}\text { Desarrollo social y } \\
\text { derechos humanos. }\end{array}$ & 2015 & $\begin{array}{l}\text { Programa de apoyo emergente (medica- } \\
\text { mentos, traslados, atención a enfermeda- } \\
\text { des o fallecimientos). } \\
\text { Talleres estatales para el fortalecimiento } \\
\text { de liderazgos. }\end{array}$ & $\begin{array}{l}\text { Todas las políticas fueron implementadas } \\
\text { por la SAICA }\end{array}$ \\
\hline Educación. & 2015 & $\begin{array}{l}\text { Programa de becas a estudiantes indíge- } \\
\text { nas y afromexicanos. }\end{array}$ & $\begin{array}{l}\text { Gestionadas y otorgadas por el Estado y } \\
\text { la SAICA. }\end{array}$ \\
\hline $\begin{array}{l}\text { Presencia en insti- } \\
\text { tuciones culturales. }\end{array}$ & 2015 & $\begin{array}{l}\text { Programa con voces afromexicanas y otro } \\
\text { de colaboración, para afromexicanos }\end{array}$ & $\begin{array}{l}\text { Radio y Televisión de Guerrero, Comuni- } \\
\text { cación Social de Guerrero, y la SAICA. }\end{array}$ \\
\hline Salud. & No & No. & No. \\
\hline Trabajo. & 2015 & $\begin{array}{l}\text { Financiación de un proyecto productivo } \\
\text { afromexicano en Acapulco. }\end{array}$ & Gestionado y otorgado por la SAICA. \\
\hline Protección judicial. & 2015 & $\begin{array}{l}\text { Programa de fianzas a indígenas y } \\
\text { afromexicanos para preliberaciones. }\end{array}$ & SAICA. \\
\hline Simbólico-cultural. & 2017 & $\begin{array}{l}\text { Declaración de Cuajinicuilapa como sitio } \\
\text { de memoria de la esclavitud y de las po- } \\
\text { blaciones africanas y afrodescendientes. }\end{array}$ & $\begin{array}{l}\text { Iniciativa de la UNESCO como parte del } \\
\text { programa La Ruta del Esclavo: Resisten- } \\
\text { cia, Libertad y Patrimonio, y del INAH. }\end{array}$ \\
\hline \multirow{2}{*}{\multicolumn{4}{|c|}{$\begin{array}{l}\text { Fuente: Elaboración propia con información de ANG (2017); García Zavaleta, B. comunicación personal, } \\
\text { bre, 2013; Sánchez, M. comunicación personal, } 26 \text { de agosto, } 2015 \text {, y datos obtenidos durante la realizac } \\
\text { de campo en Cuajinicuilapa y Chilpancingo, Guerrero en agosto de } 2015 . \\
\qquad \text { Cuadro 2. Políticas de acción afirmativa en Oaxaca de } 1990 \text { a } 2015\end{array}$}} \\
\hline & & & \\
\hline Variable & Fecha & Política afirmativa & Descripción \\
\hline Simbólica-cultural. & 1990 & $\begin{array}{l}\text { Programa Cimarrones en la Radio del } \\
\text { Instituto Nacional Indigenista. }\end{array}$ & $\begin{array}{l}\text { Dedicado a la presencia cultural de la } \\
\text { boblación negra en la región. }\end{array}$ \\
\hline Simbólica-cultural. & 2000 & Revista Fandango. & Publicada por el CCDI. \\
\hline Simbólica-cultural. & 2011 & $\begin{array}{l}\text { Festival Fiestas de Mayo dedicado a la } \\
\text { cultura afrodescendiente. }\end{array}$ & $\begin{array}{l}\text { Se presentaron las danzas afromexicanas } \\
\text { de diversos municipios. Organizado por la } \\
\text { Secretaría de Cultura y las Artes de Oaxaca. }\end{array}$ \\
\hline Simbólica-cultural. & 2013. & Día del Pueblo Negro Afromexicano. & $\begin{array}{l}\text { El } 22 \text { de agosto de 2013, por medio de } \\
\text { decreto. }\end{array}$ \\
\hline Educación. & 2015 & Becas. & Otorgadas por el PUIC-UNAM. \\
\hline
\end{tabular}




\begin{tabular}{|c|c|c|c|}
\hline $\begin{array}{l}\text { Representación en } \\
\text { instituciones políti- } \\
\text { cas y culturales. }\end{array}$ & 2011 & $\begin{array}{l}\text { Departamento de Atención al Pueblo } \\
\text { Afromexicano y a la Mujer Indígena y } \\
\text { Afromexicana. } \\
\text { Delegado afromexicano en el Consejo } \\
\text { Consultivo de la CDI. } \\
\text { Dirección de Pueblos Negros Afromexi- } \\
\text { canos del Ayuntamiento de Pinotepa } \\
\text { Nacional. } \\
\text { Consejo Municipal Afromexicano de la } \\
\text { Villa de Tututepec. }\end{array}$ & $\begin{array}{l}\text { Humberto Hebert Silva y Beatriz Amaro } \\
\text { Clemente han sido dos de los jefes del } \\
\text { Departamento de Atención al Pueblo } \\
\text { Afromexicano. } \\
\text { Juliana Acevedo Ávila ha sido jefa del } \\
\text { Departamento de la Mujer Indígena y } \\
\text { Afromexicana y miembro del Consejo Con- } \\
\text { sultivo de Pueblos Indígenas y Afromexica- } \\
\text { no de Oaxaca. } \\
\text { Eva Gasga Noyola ha sido la consejera } \\
\text { estatal de la CDI. }\end{array}$ \\
\hline Salud. & No & No & No \\
\hline Trabajo. & No & No & No \\
\hline Protección judicial. & No & No & No \\
\hline
\end{tabular}

Fuente: Elaboración propia con información de Acevedo Ávila, J., comunicación personal, 10 de marzo, 2017; Periódico Oficial. Gobierno del Estado de Oaxaca. Cuarta sesión. Tomo XCV. N. 38 (Septiembre 21, 2013); Reyes et al. (2012); Reyes, I., comunicación personal, 24 de febrero, 2017, y datos obtenidos durante trabajo de campo en Pinotepa Nacional, Oaxaca en noviembre de 2015.

Cuadro 3. Logros: respuesta del Estado por medio de políticas multiculturales

\begin{tabular}{lll}
\hline Reconocimiento constitucional a nivel federal. & No. & No. \\
Reconocimiento constitucional a nivel estatal & Sí. & Guerrero y Oaxaca. \\
Inclusión de la variable afromexicana en el censo oficial. & No. ElC, 2015. \\
Campañas de sensibilización y visibilización. & Estatal. & Guerrero y Oaxaca. \\
Reconocimiento y derechos colectivos de la tierra. & No. & No. \\
Mecanismos para luchar contra la discriminación racial. & No. & Nivel federal. \\
Formulación y aplicación de políticas públicas. & Sí. & Guerrero y Oaxaca. \\
Formulación y aplicación de políticas de acción afirmativa. &
\end{tabular}

Fuente: Elaboración propia con base en los resultados del estudio de caso.

\section{Conclusión: logros, limitaciones y desafíos}

Las políticas multiculturales son dispositivos específicos que se instauran en cada país. La movilización etnopolítica afromexicana ha logrado algunas conquistas de políticas multiculturales como el reconocimiento constitucional a nivel estatal, la aplicación de la EIC 2015, y la aplicación de políticas de acción afirmativas. Sin embargo, debido al modo de interactuar con el movimiento, se identifica una falta de voluntad política y resistencia hacia el tema de parte del Estado mexicano y un escenario contradictorio de contención y limitación en las políticas multiculturales implementadas. No obstante, se han experimentado transformaciones sociales como el empoderamiento de grupos de mujeres afromexicanas, aunque en distintas formas y con características propias.

Los representantes de la voz del pueblo afromexicano son las organizaciones citadas durante el desarrollo del artículo. Aunque las organizaciones reclaman las mismas demandas, la concentración de la representación y del poder en 
cuanto a la toma de decisiones en un número reducido de organizaciones ha resultado en múltiples fracturas y rupturas. Hay falta de unidad, divergencias en las rutas de trabajo y una constante lucha por el poder. Por tanto, las organizaciones han buscado posicionar su agenda por separado, factor que las ha llevado a multiplicar sus esfuerzos y a tener antagonismos y luchas de poder y protagonismo. Se advierte que la movilización se ha politizado por acceder a recursos económicos o beneficios políticos ante el auge de la cuestión afrodescendiente.

Por otro lado, la mayoría de los líderes de las organizaciones más activas colaboran en instituciones gubernamentales o han desarrollado una carrera política. Lo que los coloca en situaciones de dicotomía y vulnerabilidad cuando se convierten en juez y parte de la movilización y existen contextos coyunturales en los que priman intereses económicos y políticos particulares. Esto ha influido en la incapacidad de construir una agenda y de trascender al nivel nacional. No obstante, esta situación ha sido aprovechada positivamente. En especial por el grupo de mujeres, quienes han intentado utilizar los medios materiales y económicos a los que tienen acceso para transmitir ese empoderamiento a las comunidades. Otra característica de la movilización es que se crean instituciones que algunas veces no llegan a operar pues son transformadas en otros cuerpos o simplemente desaparecen.

En la Costa Chica existen múltiples identificaciones que se refieren a las formas de nombrar la diferencia "afro" en un mismo sujeto. En consecuencia, es muy difícil que haya consenso para una categoría. De hecho, Hoffmann (2006) y Lewis (2012) han afirmado que no existe una identidad colectiva afromexicana. Acerca de esto, el artículo ha mostrado que el posicionamiento de la categoría afromexicano ha desatado debates, divergencias y enfrentamientos que frenan la organización.

En algunas interacciones también se observa un cierto grado de prácticas racistas institucionales que se han trasladado e interiorizado en el imaginario colectivo. México ha implementado mecanismos para luchar contra estas prácticas; sin embargo, de nada sirve tener un vasto repertorio legislativo, instituciones y planes, si no se acepta e interioriza la problemática en el imaginario político y social. En este contexto, ninguna política multicultural servirá para conquistar la plena inclusión de la población. Queda pendiente para otro trabajo una reflexión que se enfoque en las cuestiones de la discriminación racial (social, institucional, etcétera).

La legislación no reducirá ni eliminará estas prácticas. Si fuera así, el pueblo indígena gozaría de mejores condiciones. De hecho, el perfil sociodemográfico muestra que los municipios con presencia afromexicana viven altos grados de pobreza, rezago social y marginación; y que, al mismo tiempo, hay municipios 
indígenas con peores condiciones. Aunque el pueblo indígena está reconocido constitucionalmente su condición no ha mejorado, no se han incluido plena y efectivamente al desarrollo del Estado y sus derechos no se respetan. Es un reconocimiento sin redistribución (Fraser, 2001).

Entonces, ¿hasta qué punto es deseable buscar el reconocimiento constitucional como principal eje político de una movilización social? Los afrodescendientes desean ser reconocidos para poder participar en la formulación de políticas públicas específicas que permitan su inclusión en el desarrollo. Sin embargo, dado el ejemplo indígena, es necesario reflexionar si la mera formulación de políticas públicas deviene en plena inclusión al desarrollo. Sobre todo, si el ser reconocido constitucionalmente garantiza la participación en la agenda pública y la plena ejecución de las políticas. Es posible decir que las limitaciones de la movilización son el modus operandi del neoliberalismo multicultural, de la resistencia del Estado, de las prácticas racistas y discriminatorias, y de las propias características de la movilización.

Los desafíos de la movilización afrodescendiente son, en primer lugar, llegar a las comunidades. Lewis (2012) muestra cómo el proceso de organización nació sin un apoyo significativo de las comunidades, y, al igual que Hoffmann (2006), que no existe una identidad colectiva afromexicana con la que las comunidades se sientan identificadas. Por ello, además de las características, esto podría ser un motivo por el que las comunidades no se han apropiado de la movilización. Otro desafío es alcanzar unidad y consensos para establecer rutas de trabajo. Por último, las organizaciones podrían reflexionar sobre la viabilidad de buscar el reconocimiento constitucional como el eje principal de la movilización en el marco del multiculturalismo neoliberal, o dejarlo como algo secundario y enfocarse en proyectos productivos y de desarrollo social desde el interior de las comunidades, ya que tal vez las políticas del reconocimiento de la diferencia cultural sean un instrumento más para la contención y la limitación de su inclusión y empoderamiento.

\section{Referencias}

Agudelo, C. (2015). Las encrucijadas del reconocimiento multicultural. Los afrodescendientes en América Latina y el Caribe. En Valero, S. \& Campos García, A. (Eds.). Identidades politicas en tiempos de afrodescendencia: auto-identificación, ancestralidad, visibilidad y derechos humanos (pp. 1-34). Buenos Aires: Corregidor. 
Agudelo, C. (2010a). Génesis de redes transnacionales. Movimientos afrolatinoamericanos en América Central. En Hoffmann, O. (Coord.). Política e identidad. afrodescendientes en México y América Central (pp. 1-13). México: INAH/CEMCa/unam-CIALC/IRD.

Agudelo, C. (2010b). Ciudadanía, identidades, multiculturalismo. Poblaciones negras en América Latina. Colombia Internacional, (71), 1-16.

Albó, X. (2002). Bolivia: From Indian and Campesino Leaders to Councilors and Parliamentary Deputies. En Sieder, R. (Ed.). Multiculturalism in Latin America, (pp. 74-102). Nueva York: Palgrave Macmillan.

Albó, X. (1994). And from Kataristas to Mnristas? The Surprising and Bold Alliance between Aymaras and Neoliberals in Bolivia. En Van Cott, D. (Ed.). Indigenous peoples and democracy in Latin America (pp. 55-799). Nueva York: St Martin's Press.

ANG (Agencia de Noticias de Guerrero). (2017, 26 de marzo). En Cuaji, Develan plaza y proclamación de memoria de la esclavitud y poblaciones afrodescendientes. Recuperado el 20 de abril de 2017, de http://www.angro.info/single-post/2017/03/26/En-Cuaji-Develan-placa -y-proclamaci\%C3\%B3n-de-memoria-de-la-esclavitud-y-poblaciones-afrodescendientes

Appiah, K. (2005). The ethics of identity. New Jersey: Princeton University Press.

Appiah, K. (1994). Identity against culture. Understandings of multiculturalism. Berkeley: University of California.

Avendaño, E. (2011). Estudio sobre los derechos de los pueblos negros de México. México: PUMC-UnAM.

Baltazar, A., Luna, X. \& Olvera, L. (2008). El cine indigenista: colección de producciones filmográficas del INI. México: CDI.

Barry, B. (2001). Culture and equality: An egalitarian critique of multiculturalism. Cambridge: Polity Press.

Benhabib, S. (2002). The claims of culture: Equality and diversity in the global era. Princeton, N. J.: Princeton University Press.

Burguete Cal y Mayor, A. (2003). The Facto Autonomous Process: New Jurisdictions and Parallel Governments in Rebellion. En Rus, J., Hernández, R. \& Kanham, M. (Eds.). Mayan lives Mayans utopia: The Indigenous Peoples of Chiapas and the Zapatista Rebellion (pp. 191218). Estados Unidos: Rowman \& Littlefield Publishers.

Canessa, A. (2016). Paradoxes of Multiculturalism. En Lehmann, D. (Ed.). The Crisis of Multiculturalism in Latin America (pp. 75-100). Estados Unidos: Palgrave Macmillan. 
Castellanos, A. (2011). Pueblos indios, racismo y estado. En Barba, C. \& Cohen, N. (Coords.). Perspectivas criticas sobre la cohesión social. Desigualdad y tentativas fallidas de integración social en América Latina (pp. 379-401). Buenos Aires: CLACso.

Cátedra de Mujeres Afromexicanas. (2016). Fundamentos Académicos. Huatulco.

CDI. (2013, 14 de agosto). En Guerrero se anuncia que la comunidad afromexicana se beneficiará con programas de la CDI. Recuperado el 22 de julio de 2015, de http://www.gob $. \mathrm{mx} / \mathrm{cdi} / \mathrm{prensa/en-guerrero-se-anuncia-que-la-comunidad-afromexicana-se-beneficiara-con}$ -programas-de-la-cdi-16055

CDI. (2012). Informe final de la Consulta para la identificación de comunidades afrodescendientes de México. México: CDI. Recuperado el 10 de octubre de 2015, de http://www. gob.mx/cms/uploads/attachment/file/37016/cdi_informe_identificacion_comunidades _afrodescendientes.pdf

CERD. (2012). Observaciones del Comité para la Eliminación de la Discriminación Racial. Recuperado el 10 de octubre de 2015, de http://www2.ohchr.org/english/bodies/cerd/docs/ CERD.C.MEX.Q.16-17.pdf

Chávez, D. (2010, 30 de junio). Tenemos una voz y nuestra propia historia: RADIO CIMARRÓN. [Entrada de Blog]. Recuperado el 16 de enero de 2016, de http://colectivoafrica.blogspot .com.es/2010_06_01_archive.html

Conapo. (2015). Anexo B. Índice de marginación por municipio, 2015. Recuperado el 22 de enero de 2016, de http:/www.gob.mx/cms/uploads/attachment/file/159048/06_Anexo_ B1.pdf

Conapo. (2010a). Índice absoluto de marginación 2000-2010. Cuadro 2.2 Población total, indicadores de marginación, e índice absoluto de marginación por entidad federativa, 2010. Recuperado el 17 de marzo de 2017, de http://www.conapo.gob.mx/work/models/ CONAPO/Resource/1755/1/images/02Capitulo.pdf

Conapo. (2010b). Índice de Marginación por Entidad Federativa y Municipio 2010. Cuadro B.12. Guerrero: Población total, indicadores socioeconómicos, índice y grado de marginación, lugar que ocupa en el contexto nacional y estatal por municipio, 2010. Recuperado el 17 de marzo de 2017, de http://www.conapo.gob.mx/work/models/CONAPO/indices_ margina/mf2010/CapitulosPDF/Anexo\%20B2.pdf

Conapo. (2010c). Índice de Marginación por Entidad Federativa y Municipio 2010. Cuadro B.20. Oaxaca: Población total, indicadores socioeconómicos, índice y grado de marginación, lugar que ocupa en el contexto nacional y estatal por municipio, 2010. Recuperado 
el 17 de marzo de 2017, de http://www.conapo.gob.mx/work/models/CONAPO/indices_ margina/mf2010/CapitulosPDF/Anexo\%20B3.pdf

Conapred. (2015). Derechos colectivos y reconocimiento constitucional de las poblaciones afromexicanas. Tomo VII. México: Segob/Conapred. Recuperado el 22 de marzo de 2016, de http:// www.conapred.org.mx/documentos_cedoc/LSD_VII_Derechoscolectivosa_INACCSS .pdf

Conapred. (2011a). Guía para la acción pública contra la discriminación y para la promoción de igualdad e inclusión de la población afrodescendiente en México. México: Conapred. Recuperado el 17 de mayo del 2017, de http://www.conapred.org.mx/userfiles/files/GAP -AFRO_2011_INACCSS.pdf

Conapred. (2011b). Documento Informativo sobre Discriminación Racial en México. México: Conapred.

Conapred. (2010). Encuesta nacional sobre la discriminación en México-ENADIS 2010. México: Conapred. Recuperado el 18 de octubre de 2014, de http://www.conapred.org.mx /userfiles/files/Enadis-2010-RG-Accss-002.pdf

Conapred. (2005). Carpeta de información básica. México: Conapred.

CNDH. (2016). Estudio especial de la CNDH sobre la situación de la población afrodescendiente de México a través de la encuesta intercensal 2015. México: CNDH. Recuperado el 24 de febrero de 2017, de http://www.cndh.org.mx/sites/all/doc/OtrosDocumentos/Doc_2016_023 .pdf

CONEVAL. (2017). ¿Qué es el indice de rezago social? Recuperado el 15 de abril de 2017 de http:// www.coneval.org.mx/Medicion/IRS/Paginas/Que-es-el-indice-de-rezago-social.aspx

CONeval. (2015). Indice de Rezago Social 2015 a nivel nacional, estatal y municipal. Población total, indicadores, indice y grado de rezago social, según entidad federativa, 2000, 2005, 2010 y 2015 .

coneval. (2010). Medición de la pobreza en México 2010, a escala municipal. México: CONEval.

Constitución Política del Estado de Guerrero (CPEG). (2016 [3, 10 y 17 de noviembre de 1917, 5 de enero de 1918]). Última modificación 8 de noviembre de 2016. Recuperado el 24 de febrero de 2017, de http://www.congresogro.gob.mx/index.php/constitucion

Constitución Política del Estado de Oaxaca (CPEO). (2016) [4 de abril de 1922]). Última modificación 31 de diciembre de 2016b. Recuperado el 24 de febrero de 2017, de http:// www.congresooaxaca.gob.mx/legislatura/legislacion/leyes/001R.pdf 
Constitución Política de los Estados Unidos Mexicanos (CPeum). (2017 [5 de febrero de 1917]). Última modificación 24 de febrero de 2017. Recuperado el 24 de febrero de 2017, de http://www.diputados.gob.mx/LeyesBiblio/pdf/1_240217.pdf

Cowan, J. (2001). Ambiguities of an emancipatory discourse: The making of a Macedonian minority in Greece. En Cowan, J., Dembour, M. \& Wilson, R. (Eds.). Culture and rights: Anthropological perspectives (pp. 152-175). Cambridge: Cambridge University Press.

De la Serna, J. M. (2010). Exploración antropológica para la formulación de la pregunta sobre las personas afromexicanas en el censo nacional de población y vivienda y en encuestas relacionadas. México: Conapred.

Dietz, G. (2017). Interculturalidad: una aproximación antropológica. Perfiles Educativos, XXXIX (156), 192-207.

Fraser, N. (2001). Recognition without ethics. Theory, Culture and Society, 18(2), 21-42.

Gobierno Federal/EzLn. (1996, 16 de febrero). Pronunciamiento conjunto que el gobierno federal y el EZLn enviarán a las instancias de debate y decisión nacional. Apartado: Compromisos del gobierno federal con los pueblos indígenas. Recuperado el 10 de abril de 2017, de http://zedillo.presidencia.gob.mx/pages/chiapas/docs/sanandres/pronuncia.html

Hale, C. (2006). Más que un indio (More than an Indian): Racial Ambivalence and Neoliberal Multiculturalism in Guatemala. Santa Fe, Nuevo México: School of American Research Press.

Hale, C. (2005). Neoliberal Multiculturalism: The Remaking of Cultural Rights and Racial Dominance in Central America. PoLAR. Political and Legal Anthropology Review, 28(1), 10-28.

Hale, C. (2002). Does Multiculturalism Menace? Governance, Cultural Rights and the Politics of Identity in Guatemala. Journal of Latin American Studies, (34), 485-52.

Hoffmann, O. \& Lara, G. (2012). Reivindicación afromexicana: formas de organización de la movilización negra en México. En Buffa, D., Becerra, M., Hamurabi, N. \& Ayala, M. (Comps.). Las poblaciones afrodescendientes de América Latina y el Caribe. Pasado, presente y perspectivas desde el siglo XXI (pp. 25-46). Córdoba, Argentina: Universidad Nacional Tres de Febrero.

Hoffmann, O. (2006). Negros y afromestizos en México: viejas y nuevas lecturas de un mundo olvidado. Revista Mexicana de Sociología, 68(1), 103-135.

Hooker, J. (2011). Indigenous Rights in Latin America. How to Classify Afro-descendants? En Eisenberg, A. \& Kymlicka, W. (Eds.). Identity Politics in the Public Realm. Bringing Institutions Back In, (pp. 104-136). Vancouver, Canadá: UBC Press. 
Hooker, J. (2010). Las luchas por los derechos colectivos de los afrodescendientes en América Latina. En Hoffmann, O. (Coord.). Politica e identidad: Afrodescendientes en México y América Central (pp. 33-64). México: INAH/UnAm/CEMCa/IRD.

INEGI. (2015a). Encuesta Intercensal 2015. Estimadores de la población total y su distribución porcentual según autoadscripción afrodescendiente por entidad federativa, sexo y grandes grupos de edad. México: INEGI.

INEGI. (2015b). Encuesta Intercensal 2015. Estimadores de la población total y su distribución porcentual según adscripción indígena por municipio y grandes grupos de edad, Guerrero. México: INEGI.

INEGI. (2015c). Encuesta Intercensal 2015. Estimadores de la población total y su distribución porcentual según adscripción afrodescendiente por municipio y grandes grupos de edad, Guerrero. México: INEGI.

INEGI. (2015d). Encuesta Intercensal 2015. Estimadores de la población total y su distribución porcentual según autoadscripción afrodescendiente por municipio, sexo y grandes grupos de edad, Oaxaca. México: INEGI.

INEGI. (2015e). Encuesta Intercensal 2015. Estimadores de la población total y su distribución porcentual según adscripción indígena por municipio y grandes grupos de edad, Oaxaca. México: INEGI.

Iturralde, G. \& Más Ferrer, C. (2015). xvi Encuentro de Pueblos Negros. El Azufre, Villa de Tututepec de Melchor Ocampo, Oaxaca. 13 y 14 de noviembre.

Kymlicka, W. (2007). Multicultural Odysseys: Navigating the new International Politics of Diversity. Oxford: Oxford University Press.

Kymlicka, W. (1995). Multicultural Citizenship: A Liberal Theory of Minority Rights. Oxford: Clarendon Press.

Lara, G. (2014). Negro-Afromexicanos: Formaciones de alteridad y reconocimiento étnico. Revista de estudos \& pesquisas sobre as Américas. Afrodescendentes na América Latina y Caribe: novos caminos, novas perspectivas em um contexto global multicultural. Dossie especial, 8(1), 149-175.

Lara, G. (2010). Una corriente etnopolítica en la Costa Chica, México (1980-2000). En Hoffmann, O. (Coord.). Politica e identidad. Afrodescendientes en México y América Central (pp. 307-329). México: INAH/UNAM/CEMCA/IRD. 
Lara, G. (2008). Politica, espacio y construcción social del poder local-regional en la Costa Chica de Oaxaca. Tesis de doctorado en Antropología. CIESAS. México.

Lewis, L. (2012). Chocolate and Corn Flour. History, Race, and Place in the Making of "Black" Mexico. Estados Unidos: Duke University Press.

López Chávez, A. (2014). La invisibilización de la población afrodescendiente durante la construcción del Estado-nación en México. Ciencias Políticas y Relaciones Internacionales. Revista de Investigación, 3(3), 57-74. Recuperado el 15 de mayo de 2015, de http://www.udla.edu .ec/wp-content/uploads/2014/11/REVISTA-POLITICA-NO.-3-VERSION-FINAL.pdf

Lucero, J. (2008). Struggles of voice. The politics of indigenous representation in the Andes. Estados Unidos: University of Pittsburgh Press.

Martínez, C. (2006). Who Defines Indigenous? Identities, Development, Intellectuals, and the State in Northern Mexico. New Jersey: Rutgers University Press.

Melucci, A. (1999). Teoría de la acción colectiva. En Melucci, A. Acción colectiva, vida cotidiana $y$ democracia (pp. 25-54). México: El Colegio de México.

México Negro. (2011). Relatoría xiII Encuentro de Pueblos Negros.

Minuta de la reunión de trabajo de la Comisión de Seguimiento del Encuentro Afromexicanos. (2013, 10 de julio). Acapulco, Guerrero.

Minuta de trabajo del 26 de enero de 2015, en donde se conformó la Coordinación Nacional de Organizaciones Afromexicanas. Pinotepa Nacional, Oaxaca.

Mitchell, K. (2004). Geographies of identity: Multiculturalism Unplugged. Progress in Human Geography, 28(5), 641-651.

Mojica, T. (2013, 18 de octubre). Iniciativa que reforma los artículos 2, 27, 28 y 115 de la Constitución Política de los Estados Unidos Mexicanos. México: Cámara de Diputados. Recuperado el 15 de octubre de 2014, de http://sitl.diputados.gob.mx/LXII_leg/cuadros_ comparativos/1PO2/1448-1PO2-13.pdf

Overmyer-Velázquez. (2010). Folkloric Poverty. Neoliberal Multiculturalism in Mexico. Pennsylvania: The Pennsylvania State University Press.

Parekh, B. (2000). Rethinking Multiculturalism. Cultural Diversity and Political Theory. UK: Palgrave Macmillan. 
Periódico Oficial. Gobierno del Estado de Oaxaca (2013, 21 de septiembre). Poder Ejecutivo. Cuarta sesión. Tomo XCV. N. 38. Oaxaca de Juárez, Oaxaca.

Phillips, A. (2007). Multiculturalism without Culture. Princeton, New Jersey: Princeton University Press.

PNUD/sEgIB. (2010). Actualidad Afrodescendiente en Iberoamérica. Estudio sobre organizaciones civiles y politicas de acción afirmativa. Madrid: SEGIB.

Postero, N. (2007). Now We Are Citizens: Indigenous Politics in Postmulticultural Bolivia. Standford, C. A.: Standford University Press.

Pronunciamiento del Taller Construcción de una Iniciativa de Ley de Derechos y Cultura de los "Pueblos Negros". Jamiltepec, Oaxaca. 11 de noviembre de 2006. En Reyes, I., Rodríguez, N. \& Ziga, F. (2012). De Afromexicanos a Pueblo Negro. México: unam.

Pronunciamiento que hacen las Organizaciones Civiles y Autoridades Municipales del Pueblo Negro Afromexicano. José María Morelos, Huazolotitlán, Oaxaca, 20 de abril de 2013.

Quecha, C. (2016). XVII Encuentro de Pueblos Negros. ¡Nunca más un México sin Afromexicanos! Mexican Times. Recuperado de http://themexicantimes.mx/xvii-encuentro-de-pueblos -negros/

Relatoría de las mesas de trabajo del Foro Afromexicanos. Por el reconocimiento constitucional de los Derechos del Pueblo de México. 22 de julio de 2007. En Reyes, I., Rodríguez, N. \& Ziga, F. (2012). De Afromexicanos a Pueblo Negro. México: unam.

Relatoría Evento Piloto. 2ndo. Coloquio Internacional Afrodescendientes. 16 y 17 de enero de 2015.

Resolución Primer Foro: Los Pueblos Negros en Movimiento por su Reconocimiento Constitucional, 2011. En Reyes, I., Rodríguez, N. \& Ziga, F. (2012). De Afromexicanos a Pueblo Negro. México: UnAM.

Remco, A. C. (s/a). Agenda por los derechos de las mujeres afromexicanas e indígenas de la Costa. Cuajinicuilapa, Guerrero. Inédito.

Reyes, I., Rodríguez, N. \& Ziga, F. (2012). De Afromexicanos a Pueblo Negro. México: unam.

Reynoso, A. (2005). Nuestra Tercera Raíz y los estudios sobre la presencia africana en México. En Velázquez, M. E. \& Correa, E. (Comps.). Poblaciones y culturas de origen africano en México (pp. 85-102). México: INAH. 
Saldívar, E. (2014). It's not Race It's Culture: Untangling Racial Politics in Mexico. Latin American and Caribbean Ethnic Studies, 9(1), 89-108. Recuperado el 12 de abril de 2017. doi: http://dx.doi.org/10.1080/17442222.2013.874644

Sarmiento, S. (2004, agosto). Recuento. El movimiento indígena en Guerrero. La Jornada. Suplemento Hojarasca, (88). Recuperado el 13 de marzo de 2017, de http://www.jornada .unam.mx/2004/08/19/oja88-guerrero.html

Sansone, L. (2007). Anti-Racism in Brazil. Nacla. Reporting on the Americas since 1967. Recuperado el 15 de abril de 2017, de https://nacla.org/article/anti-racism-brazil

Wade, P. (2008). Población negra y la cuestión identitaria en América Latina. Universitas Humanistica, (65), 117-137.

Wade, P. (2000). Raza y etnicidad en Latinoamérica. Quito: Abya-Yala.

Wieviorka, M. (2014). The End of Multiculturalism. Recuperado el 13 de marzo de 2017, de http://wieviorka.hypotheses.org/321

Van Cott. D. (2001). Explaining Ethnic Autonomy Regimes in Latin America. Studies in Comparative International Development, 35(4), 30-58.

Van Cott, D. (2000a). Latin America: Constitutional Reform and Ethnic Rights. Parliamentary Affairs, 53(1), 41-54.

Van Cott, D. (2000b). The friendly liquidation of the past: The politics of diversity in Latin America. Pittsburg: University of Pittsburg Press.

Ziga, F. (2015). Historizar la región: Movimiento social y reconocimiento de comunidades negras en Oaxaca. Ponencia presentada en el Coloquio Internacional Afroamérica. México: UnAM.

Ziga, F. (2008, 5 de agosto). Prólogo al libro "Costumbres y tradiciones de los pueblos negros de la Costa Chica de Oaxaca" de Israel Reyes Larrea. [Entrada de blog]. Recuperado el 13 de marzo de 2017, de http://francisco-ziga.blogspot.com.es/2008/05/prologo-al-libro-costumbres-y.html

Ziga, F. (1998). Clases y movimientos sociales en la Costa de Oaxaca. 1973-1996, México. Tesis de licenciatura en Sociología Rural. Universidad Autónoma Chapingo. México. 